\title{
Correlation between physicochemical changes of seeded and seedless watermelons during postharvest storage
}

\section{Maimunah Mohd Ali ${ }^{*}$, Norhashila Hashim and Siti Khairunniza Bejo}

\author{
Department of Biological and Agricultural Engineering, \\ Faculty of Engineering, \\ Universiti Putra Malaysia, \\ 43400 Serdang, Selangor, Malaysia \\ Fax: +603-89466425 \\ Email: maimunah_mohdali@ymail.com \\ Email: norhashila@upm.edu.my \\ Email: skbejo@upm.edu.my \\ *Corresponding author
}

\section{Rosnah Shamsudin}

Department of Food and Process Engineering,

Faculty of Engineering,

Universiti Putra Malaysia,

43400 UPM Serdang, Selangor, Malaysia

Email: rosnahs@upm.edu.my

\begin{abstract}
The physicochemical changes in fruits can be influenced by postharvest handling during the storage period. The physicochemical properties (firmness, soluble solids content, $\mathrm{pH}$, moisture content, and colour) were analysed over seven interval days to observe the changes between the seeded and seedless watermelons. The results indicated a decrease in the firmness, soluble solids content, and moisture content values, whereas the $\mathrm{pH}$ values increased for both seeded and seedless watermelons. The $\mathrm{L}^{*}, \mathrm{~b}^{*}$, and chroma values increased whereas the $\mathrm{a}^{*}$ value reduced. The hue angle value increased for both seeded and seedless watermelons. Principal component analysis (PCA) was used to determine the quality changes of both varieties and correlations among the physicochemical properties of watermelon samples. The findings indicated that PCA has the potential to characterise quality changes patterns in the seeded and seedless watermelons during storage and could establish the basis of major impact on the determination of fruit quality.
\end{abstract}

Keywords: colour; watermelon; quality; storage.

Reference to this paper should be made as follows: Ali, M.M., Hashim, N., Bejo, S.K. and Shamsudin, R. (2020) 'Correlation between physicochemical changes of seeded and seedless watermelons during postharvest storage', Int. J. Postharvest Technology and Innovation, Vol. 7, No. 1, pp.73-86. 
Biographical notes: Maimunah Mohd Ali is a Research Scholar under the guidance of Associate Professor Ir. Dr. Norhashila Hashim. Her main interests focus on the agricultural process engineering, food science and technology, postharvest engineering as well as image processing. Currently, she is doing her PhD study at the Department of Biological and Agricultural Engineering, Faculty of Engineering, Universiti Putra Malaysia.

Norhashila Hashim is an Associate Professor at the Department of Biological and Agricultural Engineering, Faculty of Engineering, Universiti Putra Malaysia. Her main scientific interests focus on the agricultural process, agriculture engineering, food science and technology, image processing, imaging science and technology, postharvest engineering as well as sensor and laser technology.

Siti Khairunniza Bejo is an Associate Professor at the Department of Biological and Agricultural Engineering, Faculty of Engineering, Universiti Putra Malaysia. Her research interests are imaging technology, precision agriculture, image processing, and sensor technology. Currently, she is the Head of Department of the Department of Biological and Agricultural Engineering, Faculty of Engineering, Universiti Putra Malaysia.

Rosnah Shamsudin is an Associate Professor at the Department of Food and Process Engineering, Faculty of Engineering, Universiti Putra Malaysia. Her research interests are process machinery design, food properties, and postharvest engineering. Her current research activities focus on the food process machinery design for small scale industry, machine design of food processes especially equipment for small and medium industry (SMI), engineering properties of foods/fruits as well as postharvest quality and handling of tropical fruits.

\section{Introduction}

Watermelon (Citrullus Lanatus) is one of the most important tropical fruits throughout the world. It ranks fifth behind durian, banana, rambutan, and pineapple for export crops from Malaysia with the production yield was estimated at approximately 150.89 million tons in 2018. Watermelon consists of numerous cultivars, including seeded, seedless, and disorder-resistant cultivars. Malaysia produces different cultivars for both seeded and seedless watermelons. The popular varieties of seeded watermelons are black beauty, new dragon, and super dragon whereas the seedless varieties are red seedless and fengshan no. 1. Watermelon is also an exotic and valuable fruit crop with a high lycopene content (Perkins-Veazie et al., 2006). The fruit can be a fundamental replacement in a healthy diet for the consumption of low sodium, cholesterol and saturated fat (Feng et al., 2013). The lycopene which is a type of carotenoid is responsible for the red colouring in numerous horticultural crops.

Similar to other fresh produce, watermelon has various cultivars which vary in shape, size, and flesh colour. For instance, the shape of the watermelon varies from spherical to oblong, whereas the colour of the flesh varies from red to yellow. In addition, the fruit has a firm rind pattern that has different thicknesses among the cultivars. The seeded watermelons tend to produce black oval seeds while the seedless cultivars have only tiny white seeds or contain no seeds at all (Yau et al., 2010). Some physicochemical and 
biochemical changes during the postharvest development of watermelon include the impact of grafting on the cucurbit hybrid rootstocks (Kyriacou and Soteriou, 2015), genetic information regarding the changes in citrulline and lycopene (Liu et al., 2010), and transmission of fruit blotch (Rushing et al., 1999).

Apart from the above, watermelon is a non-climacteric fruit which does not undergo a continuous process to ripen after being harvested (Wechter et al., 2008). Hence, high-quality watermelons are harvested at the appropriate ripening stage with respect to the appearance of the fruit. There is no proper way of knowing the ripeness of watermelon as the harvesting process is judged according to the skill and expertise of the farmers. Normally, the farmers harvest the fruit based on the sound produced when the watermelon is tapped. If the watermelon produces a dull sound, it indicates a mature fruit. Some other criteria would be subjected to the colour of the part of the watermelon that touches the base surface or the ground. The part of the fruit located at the base surface changes to a yellow tinge by the time the fruit is ripe (Ibarra-Garza et al., 2015). Moreover, the drying of the ends of the watermelon tendrils also indicates that maturity approaches as the end tendrils detach from the fruit stem. Due to the consumer preference for sweet and juicy watermelon flesh, the soluble solids content (SSC) is a crucial component in assessing the sweetness level of the fruit. The conventional method to determine the sugar content of the fruit is by testing the juice using a refractometer upon cutting the watermelon into random samples.

The changes in the physicochemical properties of watermelon during the postharvest storage period are widely explored but the information on the correlation between physicochemical changes of seeded and seedless watermelons is still limited. Perkins-Veazie and Collins (2004) investigated the effect of fresh-cut processing on the lycopene content and quality parameters of watermelon using modified atmosphere storage. In a similar manner, Yau et al. (2010) studied the physicochemical properties and optimum eating quality of seedless watermelon during storage at room temperature. Postharvest storage is important in improving the quality and processing of the watermelons, as well as implementing a system for postharvest technology. Watermelon quality is basically influenced by the maturity level of the fruit. The physicochemical changes occur corresponding to the maturity stages which could affect the quality characteristics, especially for storage and commercialised lines. The physicochemical and environmental properties are subjected to the main components of determining fruit quality in terms of texture, flavour, colour, and shelf-life (Wani et al., 2014). With respect to this state, the determination of watermelon quality during storage is essential for monitoring fruit maturity and the freshness of the fruit.

Since the production of commodities does not solely depend on the sorting and grading processes, the present work on postharvest storage of watermelon could produce high-quality watermelon products and contribute to decisive quality parameters at a suitable maturity level. As the quality parameters of watermelon change rapidly during the storage period, the postharvest handling of the fruit could affect the choice of consumers. The quality parameters determined in this study could become a benchmark information for producers in distinguishing different types of watermelon cultivars. Therefore, the aim of this research is to compare the changes in the physicochemical properties of watermelon during postharvest storage for two types of variety, namely seeded and seedless. The relationship among the physicochemical properties was also examined. 


\section{Materials and methods}

\subsection{Sample preparation}

Two cultivars from the seeded and seedless varieties, black beauty and red seedless, respectively were obtained from a local farm orchard located at $4^{\circ} 02^{\prime}$ north latitude and $101^{\circ} 18^{\prime}$ east longitude in Perak, Malaysia. The freshly harvested ripe seeded and seedless watermelons were obtained on the same day at the end of November 2015 to avoid seasonal variances of the physicochemical properties between the cultivars. The fruit samples were cleaned from any dirt or defect before analysis. The planting was cultivated on alkaline clay-loam soil with daily fertigation of $120 \mathrm{~N}$ : $170 \mathrm{P}: 20 \mathrm{~K}$ in $\mathrm{g} / \mathrm{m}^{3}$, provided through a drip irrigation system ten days after transplanting. The row planting distance was $1.0 \mathrm{~m}$ and the space between the rows was $3.0 \mathrm{~m}$. A completely randomised design was applied, consisting of three replicate plots per cultivar. The fresh watermelons were transported to the laboratory of the Department of Agricultural and Biological Engineering, Faculty of Engineering, Universiti Putra Malaysia. The seeded and seedless watermelons of almost similar size and free from any external defects were classified manually and stored in cold storage at $10^{\circ} \mathrm{C}$ and $85 \%$ relative humidity $(\mathrm{RH})$ for 21 days (Mohd Ali et al., 2017). The measurement of the physicochemical properties of each of the 70 black beauty and 70 red seedless were determined during three weeks of storage. A total of 140 watermelons were evaluated in this study. Ten watermelons of each cultivar were chosen randomly at each of seven interval days of $0,4,8,12,15,18$, and 21 days for the measurement of the physicochemical properties, i.e., firmness, $\mathrm{SSC}, \mathrm{pH}$, moisture content $(\mathrm{MC})$, and colour parameters $\left(\mathrm{L}^{*}, \mathrm{a}^{*}, \mathrm{~b}^{*}, \mathrm{C}\right.$, and $\mathrm{h}$ ).

\subsection{Determination of physicochemical properties}

\subsubsection{Firmness}

For the firmness determination, a hand-held penetrometer (GY-1, G-tech Co. Ltd., China) with a $3.5 \mathrm{~mm}$ diameter plunger tip was used. The plunger tip was inserted into the watermelon flesh at six different locations to obtain the firmness values. The maximum force exerted upon the insertion of the plunger tip into the flesh was taken as a reading and the values were measured in $\mathrm{N} / \mathrm{m}^{2}$.

\subsubsection{Soluble solids content}

The same fruit samples used in the firmness measurement were blended using a fruit blender (Panasonic MX-801HS Blender, Malaysia) to extract the watermelon juice. The juice was extracted and filtered using a muslin cloth. The SSC of the filtered juice was measured by a handheld digital refractometer (Pal-1, Atago Co., Tokyo, Japan). A few drops of the filtered juice were placed on the prism to obtain the brix values. The SSC measurements were repeated in three replications to obtain the average brix value.

\subsection{3 $\mathrm{pH}$}

The watermelon juice from the SSC measurement was used for the determination of the $\mathrm{pH}$. The $\mathrm{pH}$ of the watermelon juice was determined using a digital $\mathrm{pH}$ metre (DPH-2, Atago Co., Tokyo, Japan). The electrode of the $\mathrm{pH}$ metre was dipped into the watermelon 
juice after calibrating it using a $\mathrm{pH} 7.00$ buffer solution. The $\mathrm{pH}$ measurements were carried out in triplicate and the $\mathrm{pH}$ values were denoted in units of $\mathrm{pH}$.

\subsubsection{Moisture content}

The watermelon flesh was diced into standard size cubes $(2 \mathrm{~cm} \times 2 \mathrm{~cm} \times 2 \mathrm{~cm})$ to obtain uniform cube samples for the MC measurement. The fruit samples were oven-dried (WS-301, Tsung Hsing Food Machinery Co. Ltd., Taiwan) for $24 \mathrm{~h}$ at $105^{\circ} \mathrm{C}$, according to the standard set by the Association of Official Analytical Chemists (AOAC International). The $\mathrm{MC}$ measurement was performed in triplicate and denoted as a percentage of wet basis $(\% \mathrm{wb})$.

\subsubsection{Colour evaluation}

The outer surface colour of the watermelon rind was measured using a handheld colorimeter (NR20XE, Shenzhen 3nh Technology Co. Ltd., China) with a measuring aperture diameter of $20 \mathrm{~mm}$. The colorimeter was calibrated with a standard white tile prior measurement. The measurement was conducted by placing the aperture of the colorimeter at the surface of the watermelon in an upright position to minimise the interruption of the light. The colour space values were denoted as $\mathrm{L}$ (whiteness or brightness/darkness), a (redness/greenness) and b (yellowness/blueness), chroma ( $\mathrm{C}$ is the colour intensity/saturation), and hue angle (h), respectively.

\subsection{Statistical analysis}

The significant differences obtained from the watermelon cultivars and storage interval days were determined using one-way analysis of variance (ANOVA). Meanwhile, the mean significant differences between the physicochemical properties (firmness, SSC, $\mathrm{pH}$, $\mathrm{MC}$, colour) on each interval day were compared using a Tukey test at $\mathrm{P} \leq 0.05$. The data was expressed as means and standard errors using the SAS software (Version 9.4, SAS Institute, Cary, NC, USA). All of the fruit samples were calculated at least in triplicate for each physicochemical analysis. The normal distribution test was carried out on the variables and residuals for each of the physicochemical property datasets. The variables of all datasets were normally distributed $(\mathrm{P} \leq 0.05)$, and the histogram of the residuals showed a normal distribution. The homogeneity test showed that the variances of residuals were homogeneous $(\mathrm{P} \leq 0.05)$. Pearson correlation analysis was performed to evaluate the relationships among the physicochemical properties of watermelons for the following attributes: firmness, SSC, $\mathrm{pH}, \mathrm{MC}, \mathrm{L}^{*}, \mathrm{a}^{*}, \mathrm{~b}^{*}, \mathrm{C}$ and $\mathrm{h}$. Meanwhile, the principal component analysis (PCA) was performed using the Unscrambler (Version 10.3, CAMO AS, Oslo, Norway) to visualise the variation among the seeded and seedless watermelons on the physical properties and colour. 


\section{Results and discussion}

\subsection{Characteristics of physical properties of watermelons}

Two different cultivars, seeded (black beauty) and seedless (red seedless) watermelons were used in this study. The physical properties of the seeded and seedless watermelons are listed in Table 1. These two cultivars of watermelons were chosen based on their shape and size, which is an important criterion for the classification of the fruits according to the standard size and grade. Four physical properties of both cultivars were examined, namely length (L), diameter (D) and the ratio of length to diameter (L/D ratio). From the table, there were slight variations in terms of length, diameter and L/D ratio of the fruits. Normally, an unripe watermelon has a higher MC, indicating that the fruit weight is heavier (Yau et al., 2010). Thus, the fruit weight becomes lighter during the ripening stage of the watermelons.

Table 1 Physical properties of watermelons.

\begin{tabular}{lccccc}
\hline \multirow{2}{*}{ Parameter } & \multicolumn{2}{c}{ Seeded } & & \multicolumn{2}{c}{ Seedless } \\
\cline { 2 - 3 } \cline { 5 - 6 } & Range & Mean $\pm S D$ & & Range & Mean $\pm S D$ \\
\hline Length, L $(\mathrm{cm})$ & $20.96-32.55$ & $26.16 \pm 1.85$ & & $16.21-29.51$ & $25.32 \pm 1.32$ \\
Weight, W $(\mathrm{kg})$ & $2.09-5.04$ & $3.49 \pm 0.48$ & & $5.20-9.90$ & $6.81 \pm 0.71$ \\
Diameter, D $(\mathrm{cm})$ & $12.19-15.60$ & $14.07 \pm 0.60$ & & $16.66-22.27$ & $19.16 \pm 1.13$ \\
L/D ratio & $1.52-2.19$ & $1.86 \pm 0.12$ & & $1.01-1.70$ & $1.32 \pm 0.12$ \\
\hline
\end{tabular}

Note: SD: standard deviation.

The range of the weight of the seeded and seedless watermelon was 2.09 to $5.04 \mathrm{~kg}$ and 5.20 to $9.90 \mathrm{~kg}$, respectively. The fruit weights were higher compared to the previous studies on other cultivars reported by Jie et al. (2014) for Qilin watermelon (3.84 to 5.60 $\mathrm{kg}$ ) and Yau et al. (2010) for red seedless watermelon (3.97 to $7.64 \mathrm{~kg}$ ). Meanwhile, the range of seeded watermelon length was from 20.96 to $32.55 \mathrm{~cm}$, while the seedless watermelon range was between 16.21 to $29.51 \mathrm{~cm}$. The fruit length results were within the range of 24.40 to $32.40 \mathrm{~cm}$, in accordance with previous research (Koc, 2007). The range of fruit diameter of the seeded and seedless watermelons was 12.19 to $15.60 \mathrm{~cm}$ and 16.66 to $22.27 \mathrm{~cm}$, respectively. The L/D ratio range of the seeded watermelon $(1.52$ to 2.19) was higher than the seedless watermelon (1.01 to 1.70$)$. The $\mathrm{L} / \mathrm{D}$ ratio in the literature was reported in the range of 1.01 to 1.03 (Yau et al., 2010). In comparison with the seedless watermelons, the weight and diameter of the cultivar markedly higher than seeded watermelons. On the contrary, the length and L/D ratio of seeded watermelons were longer than the seedless watermelons. For both seeded and seedless watermelons, the physical properties of the fruit including length, weight, diameter, and L/D ratio varied due to the difference in terms of size and shape. 


\subsection{Changes of firmness, SSC, $\mathrm{pH}$, and MC during storage period}

The ANOVA of firmness, SSC, $\mathrm{pH}$, and $\mathrm{MC}$ of the watermelon is summarised in Table 2. The postharvest storage days were evaluated based on the cultivars of the watermelons which were influenced by the changes in the physicochemical properties. The study had two independent variables which were type of cultivars (two levels) and storage days (seven levels). The one-way ANOVA analysis compares the mean differences between the two independent variables or factors. Hence, the purpose of the analysis is to find the interaction between the type of cultivars and storage days on the physicochemical properties of the watermelon. Based on the results, there was a significant difference in firmness, $\mathrm{SSC}, \mathrm{pH}$, and $\mathrm{MC}$ of the watermelon on different storage days. The seeded watermelon had slightly higher values than seedless watermelon for firmness, SSC, and MC. Meanwhile, the $\mathrm{pH}$ had a lower value in seeded watermelon as compared to the seedless watermelon. The analysis of $\mathrm{SSC}, \mathrm{pH}$, and $\mathrm{MC}$ values also indicated a significant difference $(\mathrm{P}<0.05)$ with respect to the different type of cultivars.

Table 2 F-values (ANOVA) of physicochemical properties of watermelons.

\begin{tabular}{lccccccccc}
\hline Factor & Firmness & SSC & $p H$ & $M C$ & $L^{*}$ & $a^{*}$ & $b^{*}$ & $C$ & $h$ \\
\hline Day & $103.90^{*}$ & $31.08^{*}$ & $18.09^{*}$ & $44.08^{*}$ & $228.56^{*}$ & $22.03^{*}$ & $55.73^{*}$ & $52.60^{*}$ & $127.54^{*}$ \\
Cultivar & $42.95^{*}$ & $1.38^{\mathrm{ns}}$ & $3.55^{\mathrm{ns}}$ & $33.35^{*}$ & $1,195.10^{*}$ & $502.76^{*}$ & $593.39^{*}$ & $670.05^{*}$ & $170.55^{*}$ \\
$\begin{array}{l}\text { Day* } \\
\text { cultivar }\end{array}$ & $3.25^{*}$ & $13.71^{*}$ & $14.08^{*}$ & $12.77^{*}$ & $0^{\mathrm{ns}}$ & $4.88^{*}$ & $1.59^{\mathrm{ns}}$ & $1.06^{\mathrm{ns}}$ & $0.15^{\mathrm{ns}}$ \\
\hline
\end{tabular}

Notes: ${ }^{\text {ns non-significant. }}$

*significant at $\mathrm{P}<0.05$.

Table 3 Firmness, $\mathrm{SSC}, \mathrm{pH}$, and MC of watermelons at different storage days

\begin{tabular}{ccccccccc}
\hline \multirow{3}{*}{ Day Seeded } & \multicolumn{5}{c}{ Seedless } \\
\cline { 2 - 9 } & Firmness & SSC & $p H$ & $M C$ & Firmness & SSC & $p H$ & $M C$ \\
\hline 0 & $5.07 \pm$ & $9.06 \pm$ & $5.27 \pm$ & $95.46 \pm$ & $4.78 \pm$ & $8.52 \pm$ & $5.60 \pm$ & $94.53 \pm$ \\
& 0.10 & 0.18 & 0.08 & 0.40 & 0.12 & 0.16 & 0.06 & 0.56 \\
4 & $4.63 \pm$ & $8.49 \pm$ & $5.63 \pm$ & $92.61 \pm$ & $4.18 \pm$ & $7.30 \pm$ & $6.01 \pm$ & $94.16 \pm$ \\
& 0.05 & 0.04 & 0.08 & 0.38 & 0.05 & 0.12 & 0.03 & 0.19 \\
8 & $4.35 \pm$ & $7.89 \pm$ & $5.88 \pm$ & $90.61 \pm$ & $3.74 \pm$ & $6.38 \pm$ & $6.56 \pm$ & $91.76 \pm$ \\
& 0.03 & 0.07 & 0.02 & $0.17 \mathrm{~d}$ & 0.05 & 0.10 & 0.12 & 0.31 \\
12 & $4.09 \pm$ & $7.57 \pm$ & $6.07 \pm$ & $88.15 \pm$ & $3.86 \pm$ & $6.85 \pm$ & $6.41 \pm$ & $91.20 \pm$ \\
& 0.03 & 0.03 & $0.03 \mathrm{c}$ & 0.13 & 0.20 & 0.68 & 0.46 & 2.05 \\
15 & $3.88 \pm$ & $7.06 \pm$ & $6.27 \pm$ & $86.88 \pm$ & $3.92 \pm$ & $8.28 \pm$ & $5.33 \pm$ & $89.97 \pm$ \\
& 0.03 & 0.08 & 0.01 & 0.11 & 0.07 & 0.07 & 0.03 & 0.51 \\
18 & $3.60 \pm$ & $6.51 \pm$ & $6.70 \pm$ & $85.61 \pm$ & $3.43 \pm$ & $7.60 \pm$ & $5.58 \pm$ & $88.80 \pm$ \\
& 0.05 & 0.11 & 0.04 & 0.29 & 0.04 & 0.07 & 0.02 & 0.32 \\
21 & $3.24 \pm$ & $5.66 \pm$ & $7.10 \pm$ & $82.79 \pm$ & $3.03 \pm$ & $6.41 \pm$ & $6.42 \pm$ & $86.43 \pm$ \\
& 0.04 & 0.13 & 0.06 & 0.93 & 0.05 & 0.23 & 0.12 & 0.52 \\
\hline
\end{tabular}

Notes: SSC: soluble solid contents.

MC: moisture content.

Data are mean values of triplicate analysis and presented as the means \pm standard errors. Mean values followed by different letters in rows indicate a significant difference at the $\mathrm{P} \leq 0.05$ level by the Tukey test. 
The changes in firmness, $\mathrm{SSC}, \mathrm{pH}$, and MC by different storage days are as shown in Table 3. The firmness values of both the seeded and seedless watermelons decreased constantly along with increasing storage days. Both cultivars showed a significant difference, ranging from 5.07 to $3.24 \mathrm{~kg} / \mathrm{cm}^{2}$ and 4.78 to $3.03 \mathrm{~kg} / \mathrm{cm}^{2}$ for the seeded and seedless watermelons, respectively. The firmness of seeded and seedless watermelons indicated the highest value of $\left(5.07 \pm 0.10 \mathrm{~kg} / \mathrm{cm}^{2}\right)$ and $\left(4.78 \pm 0.12 \mathrm{~kg} / \mathrm{cm}^{2}\right)$ at day 0 , and significantly declined to the lowest firmness value of $\left(3.24 \pm 0.04 \mathrm{~kg} / \mathrm{cm}^{2}\right)$ and $(3.03$ $\left.\pm 0.05 \mathrm{~kg} / \mathrm{cm}^{2}\right)$ at day 21 , respectively. Similar reports have been made for other watermelon cultivars such as sugar baby (Quek et al., 2007), Kylin (Mao et al., 2016), as well as celebration, gallery, Pegasus, and Torpilla (Kyriacou and Soteriou, 2015). The fruit softening could be caused by different aspects including the biochemical changes of the cell wall, degradation of polysaccharides, and dissolution of the middle lamella (Ibarra-Garza et al., 2015).

The SSC values of seeded watermelons significantly decreased along the storage days. On the other hand, the SSC values declined until day 12 and slightly increased at day 15 for seedless watermelons during storage. There was no significant difference in SSC of the seeded watermelon at day 8 and day 12. Under the storage conditions, the SSC declined from 9.06 to 5.66 Brix for the seeded watermelon and 8.52 to 6.41 brix for the seedless watermelon. The decline in the SSC values might be due to the degradation of sugars to acid (Tirkey et al., 2014). The degradation of sugars resulted in a decrease in the yield of sugars and reduce food quality. The highest decline in SSC values was revealed on day 21 (5.66) and day 8 (6.38) for the seeded and seedless watermelons, respectively. This indicated that the sweetness level of the watermelons decreased with the passage of storage days for seeded watermelons. Meanwhile, the SSC values slightly increased at day 15 before it gradually decreased until day 21 for seedless watermelons. This could be due to the fact that the rise in SSC was attributed to the respiration process of the fruit after two weeks storage period (Yau et al., 2010). The findings were consistent with prior studies performed by Jha et al. (2012) on apples, as changes in SSC were also observable during postharvest storage. Similar trends were obtained despite the different crop used in the research study.

As for $\mathrm{pH}$ determination, the lowest $\mathrm{pH}$ was observed with a value of $5.27 \pm 0.08 \mathrm{pH}$ (day 0) and $5.33 \pm 0.03 \mathrm{pH}$ (day 15) for the seeded and seedless watermelons, respectively. A marked increase in the $\mathrm{pH}$ was observed with increasing storage days from 5.27 to 7.10 and 5.60 to 6.42 for the seeded and seedless watermelons, respectively. Carvalho and Betancour (2015) reported that the $\mathrm{pH}$ values in blackberry fruits increased with storage day, suggesting that there was a strong influence on the fruit quality and the variability among the cultivars. In addition, Yau et al. (2010) also noted that the pH values of watermelon remain fairly constant and slightly increased during the storage period which might be due to the rise in the deterioration of the fruit. The $\mathrm{pH}$ values of watermelon also vary with different types of cultivars and environment of fruit production (Perkins-Veazie et al., 2012).

On the other hand, the changes in MC of the seeded and seedless watermelons also showed a similar trend by storage day. The highest MC was observed at day 0 with the MC value of $95.46 \%$ and $94.53 \%$ wet basis (wb) for the seeded and seedless watermelons, respectively. Meanwhile, the lowest MC was determined at day 21 with percentage wb values of $82.79 \%$ and $86.43 \%$ for the seeded and seedless watermelons, respectively. There was also a significant effect on almost all storage days except for day 8 for the seeded watermelons. A different trend in MC change was observed in the 
seedless watermelon since a significant effect was exhibited on day 0 . The differences in terms of MC could be attributed to the variability of the watermelon cultivars. It was also found that the $\mathrm{MC}$ increased gradually along the storage period due to the rise in water content through the flesh of the fruit (Shamsudin et al., 2007). Among these watermelon cultivars, both seeded and seedless watermelons possessed similar quality attributes values on firmness, SSC, $\mathrm{pH}$, and $\mathrm{MC}$. These observations indicated that the physicochemical properties of both watermelon cultivars had similar quantitative measurements at different storage days.

\subsection{Colour evaluation}

The findings of the colour changes in both the seeded and seedless watermelons during the seven storage days are shown in Figure 1. There were significant changes in the colour parameters by the storage day which could be related to the degradation of lycopene during postharvest. The colour intensity variation of watermelons was associated with the lycopene synthesis during the storage of the fruit (Yau et al., 2010). The $\mathrm{L}^{*}$ gradually increased and $\mathrm{a}^{*}$ decreased along with storage days (day 0 , day 4 , day 8 , day 12 , day 15 , day 18 , day 21 ) in both the seeded and seedless watermelons. In this case, the increasing $L^{*}$ value is may have resulted from the postharvest cultivar performance with respect to the maturity for the colour changes on the outer surface of the watermelon. No significant difference was observed for $\mathrm{L}^{*}$ for the seeded and seedless watermelons, which increased by $21 \%$ and $12 \%$ at day 4 , respectively [Figure 1(a)]. As for the $\mathrm{a}^{*}$ value, there was no significant difference in both the seeded and seedless watermelons [Figure 1(b)]. The trend of $a^{*}$ value which represents the redness index was quite similar for both types of cultivar. Meanwhile, the $b^{*}$ value increased along with storage day for both types of cultivar [Figure 1(c)]. Nevertheless, there was no significant difference reported for the seeded watermelon for the $b^{*}$ value. The variation in the $\mathrm{L}^{*}, \mathrm{a}^{*}$, and $\mathrm{b}^{*}$ values of the seeded and seedless watermelons could be due to the different textures that affect the firmness changes on the external surface or skin colour of the fruit.

On the other hand, the results exhibited an increase in the chroma values for the seedless watermelon with a significant difference at day 21 [Figure 1(d)]. However, there was no significant difference in the chroma value changes for the seeded watermelon. The chroma values revealed only slight changes with no clear trend noticed along with the change in storage day. Similar results were reported by Ibarra-Garza et al. (2015) who indicated that the decline in the chroma values could probably reflect the absence of lightness and a minor discrepancy in hue tones of the surface of the fruit. The hue values also exhibit a variation over the change in storage day for both the seeded and seedless watermelons [Figure 1(e)]. The findings show there were significant differences in colour parameters of seeded and seedless watermelons throughout the storage days. Since there was a variation in the colour parameters of the seedless watermelon, it could be implied that colour evaluation is a feasible method to observe the colour changes throughout the ripening process of the fruit. 
Figure 1 Changes in colour parameter values of seeded and seedless watermelons during storage, (a) $L^{*}$ value (b) a* value (c) b* value (d) chroma value (e) hue value

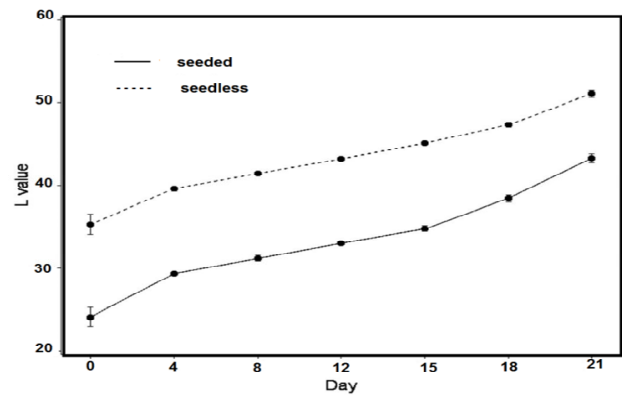

(a)

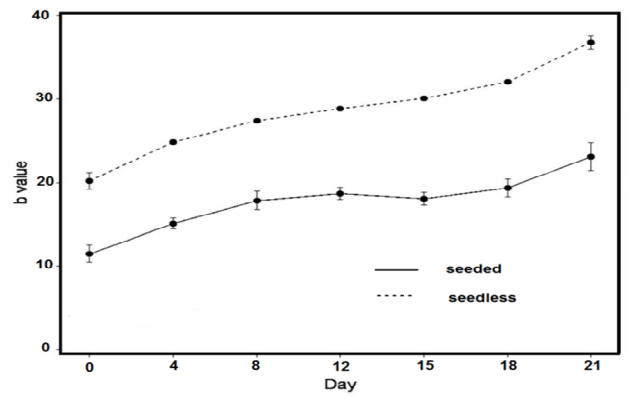

(c)

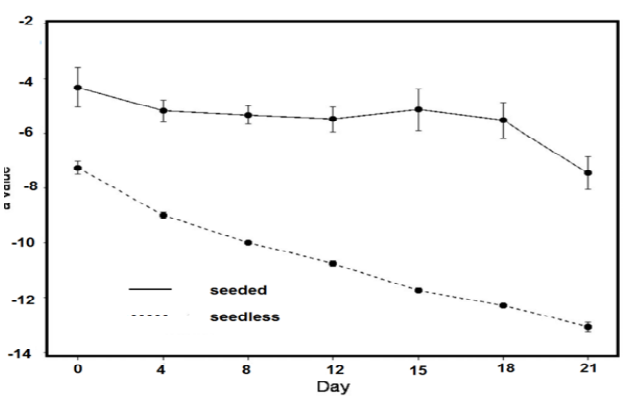

(b)

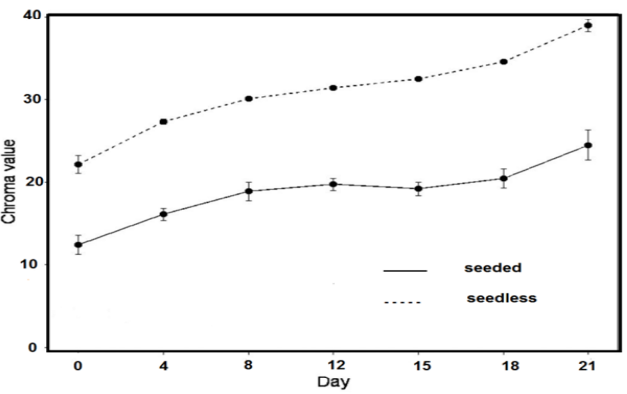

(d)

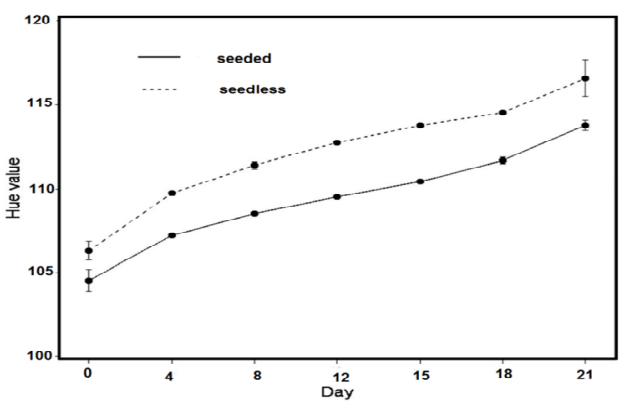

(e)

Notes: The corresponding values represent the mean of three replications and their standard error bars. Different letters indicate statistical difference by the Tukey test $(\mathrm{p}<0.05)$.

In contrast, the ANOVA of the colour changes indicated that both the storage day and the type of cultivar indicated significant differences for all colour parameters (Table 2). Nevertheless, there was no interaction between the different storage days and the type of cultivar for all the colour parameters, except for the $a^{*}$ value. The effect of postharvest storage on the physicochemical properties of the seeded and seedless watermelons was studied in the present study, considering the classification of the fruit according to its category. The discrepancies of the colour parameters in watermelons could also be due to the low temperature in the field with regard to normal colour development (Showalter, 1960). The determination of colour changes is essential in order to maintain the shelf life 
of the fruit. Similar trends were observed for the colour values ( $L^{*}, a^{*}, b^{*}, C$, and $\left.h\right)$ of seeded and seedless watermelons along the storage days. These observations suggested that the variation of colour changes of both cultivars caused by a longer storage period of the fruit (Tlili et al., 2011).

\subsection{Correlation between physicochemical properties}

Pearson correlation coefficients between the physicochemical properties from the seeded and seedless watermelons are summarised in Table 4. The SSC of the watermelons were positively correlated to the firmness $(r=0.604, p \leq 0.05)$. It can be inferred that the SSC was strongly associated with the firmness since it related to the fruit spoilage during the ripening process. The correlation analysis showed a negative correlation between $\mathrm{MC}$ and the SSC together with $\mathrm{pH}$ of the watermelons. This indicated that the decrease of $\mathrm{MC}$ also influenced the reduction of the SSC as the sweetness level of the fruit was decreased (Yau et al., 2010). The study also proved that the correlation between the colour parameters $\left(\mathrm{L}^{*}, \mathrm{a}^{*}, \mathrm{~b}^{*}, \mathrm{C}\right.$, and $\mathrm{h}$ ) with the firmness, $\mathrm{SSC}, \mathrm{pH}$, and $\mathrm{MC}$ could be used to determine the properties that affected the colour changes of the watermelon samples. The $L^{*}, b^{*}$, and $h$ parameters were positively correlated with the $\mathrm{MC}(\mathrm{r}=0.741, \mathrm{r}=0.463$, and $\mathrm{r}=0.906$ ), respectively. The $\mathrm{a}^{*}$ and $\mathrm{C}$ parameters were observed to be positively correlated with the $\mathrm{pH}(\mathrm{r}=0.422$, and $\mathrm{r}=0.661)$, respectively. The correlation analysis revealed that the fruit firmness could affect the $\mathrm{L}^{*}, \mathrm{a}^{*}$, and $\mathrm{b}^{*}$ parameters, whereas the fruit $\mathrm{pH}$ was associated with the changes of the $\mathrm{C}$ and $\mathrm{h}$ parameters. Further work is required to investigate the influence of the physicochemical properties on the colour changes of the watermelon rind surface.

Table 4 Pearson correlation coefficients for physicochemical properties of watermelons.

\begin{tabular}{lcccccccc}
\hline & Firmness & SSC & $p H$ & $M C$ & $L^{*}$ & $a^{*}$ & $b^{*}$ & $C$ \\
\hline $\mathrm{SSC}$ & $0.604^{*}$ & & & & & & & \\
$\mathrm{pH}$ & $0.509^{*}$ & $-0.231^{*}$ & & & & & & \\
$\mathrm{MC}$ & $-0.909^{*}$ & $-0.453^{*}$ & $-0.743^{*}$ & & & & & \\
$\mathrm{~L}^{*}$ & $-0.851^{*}$ & $-0.413^{*}$ & $-0.411^{*}$ & $0.741^{*}$ & & & & \\
$\mathrm{a}^{*}$ & $0.645^{*}$ & $0.169^{*}$ & $0.422^{*}$ & $-0.597^{*}$ & $-0.871^{*}$ & & & \\
$\mathrm{~b}^{*}$ & $-0.628^{*}$ & $-0.350^{*}$ & $-0.131^{\text {ns }}$ & $0.463^{*}$ & $0.871^{*}$ & $-0.878^{*}$ & & \\
$\mathrm{C}$ & $-0.033^{\text {ns }}$ & $-0.366^{*}$ & $0.661^{*}$ & $-0.261^{*}$ & $0.328^{*}$ & $-0.354^{*}$ & $0.651^{*}$ & \\
$\mathrm{~h}$ & $-0.788^{*}$ & $-0.083^{\text {ns }}$ & $-0.917^{*}$ & $0.906^{*}$ & $0.700^{*}$ & $-0.627^{*}$ & $0.420^{*}$ & $-0.400^{*}$ \\
\hline
\end{tabular}

Notes: ${ }^{\mathrm{n}}$ non-significant.

*significant at $\mathrm{P}<0.05$.

Based on the PCA the loading plot of the physicochemical properties and colour changes of seeded and seedless watermelons is shown in Figure 2. The principal components (PC) which are first $(\mathrm{PC} 1)$ and the second (PC2) represented $72 \%$ and $25 \%$ of the variance, respectively with a total of $97 \%$ of the variation. The loading plot delivered the information on the correlations among the physicochemical properties and colour changes of the watermelon samples. Taking into account the properties at the centre of the loading plot are not significant properties for the results the properties located in the outer ellipses are more significant than the inner ellipses. The $\mathrm{pH}$ and $\mathrm{MC}$ were loaded 
positively on $\mathrm{PC} 1$ and $\mathrm{PC} 2$, whereas $\mathrm{L}^{*}, \mathrm{~b}^{*}, \mathrm{C}$, and h were loaded positively on PC1 in the outer ellipses, respectively. Meanwhile, a* was loaded negatively on PC1, whereas firmness and $\mathrm{MC}$ were loaded negatively on both PC1 and PC2, respectively. Among all of the physicochemical properties and colour, there is no parameter located inside the inner ellipses of the PCA loading plot.

Figure 2 Loading plot of the physicochemical properties and colour changes of seeded and seedless watermelons in PC1 and PC2

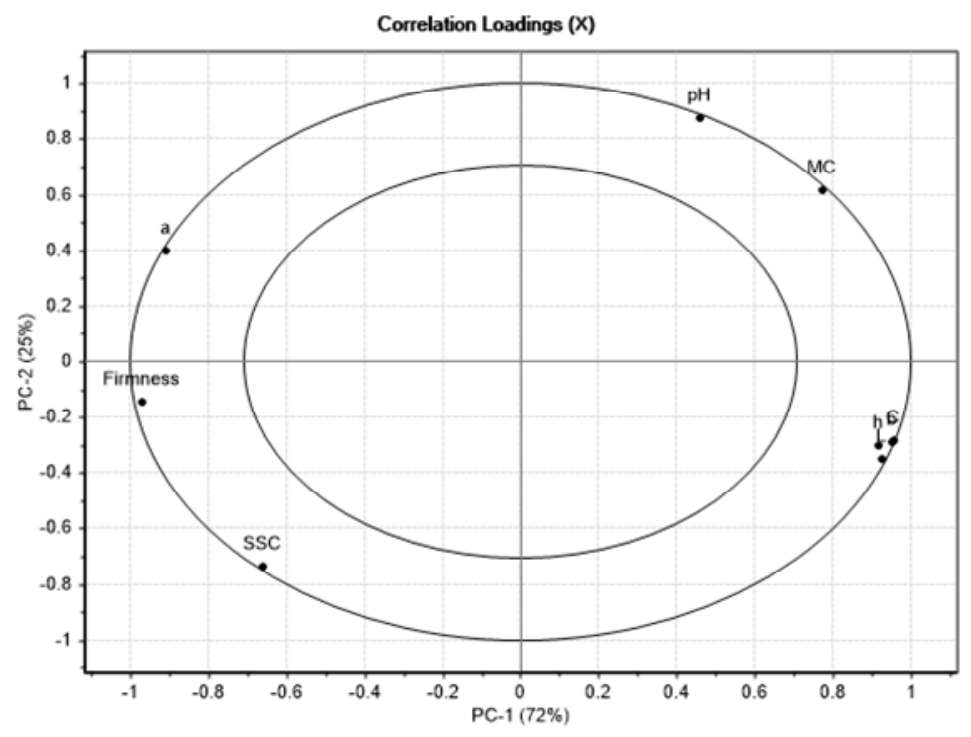

\section{Conclusions}

In the present study, the physicochemical properties were evaluated over different storage days for the seeded and seedless watermelons. The valuable information obtained regarding the determination of the physical properties is important for the postharvest storage and processing of the fruit since it provides guidelines regarding the appropriate storage days for shelf-life preservation of the watermelon. It can be noted that there was a significant difference in firmness, $\mathrm{SSC}, \mathrm{pH}$, and $\mathrm{MC}$ of the watermelon on different storage days. The seeded watermelon had slightly higher values than seedless watermelon for firmness, SSC, and MC. On the contrary, the $\mathrm{pH}$ had a lower value in seeded watermelon as compared to the seedless watermelon. Correlation analysis showed that $\mathrm{MC}$ and $\mathrm{pH}$ were the most important parameters in determining the physicochemical properties of seeded and seedless watermelons. As revealed from the PCA score plot, the physicochemical properties for seeded and seedless watermelons could be used to evaluate different environmental aspects in such a way to improve fruit quality and storage control to meet the requirements of postharvest handling of watermelons. The scientific investigation obtained herein also presents guideline towards the selection of suitable postharvest storage for the watermelon industry to deliver the highest quality of fruit. Hence, the research findings could provide the necessary knowledge for evaluating the commercial value of fresh watermelons. 


\section{References}

Carvalho, C.P. and Betancour, J.A. (2015) 'Quality characterization of Andean blackberry fruits (Rubus glaucus Benth.) in different maturity stages in Antioquia', Agronomía Colombiana, Vol. 33, No. 1, pp.74-83.

Feng, M., Ghafoor, K., Seo, B. et al. (2013) 'Effects of ultraviolet-C treatment in Teflon-coil on microbial populations and physico-chemical characteristics of watermelon juice', Innovative Food Science and Emerging Technologies, Vol. 19, pp.133-139, Elsevier Ltd.

Ibarra-Garza, I.P., Ramos-Parra, P.A., Hernández-Brenes, C. et al. (2015) 'Effects of postharvest ripening on the nutraceutical and physicochemical properties of mango (Mangifera indica $L$. cv Keitt)', Postharvest Biology and Technology, Vol. 103, pp.45-54, Elsevier India Pvt Ltd.

Jha, S.N., Rai, D.R. and Shrama, R. (2012) 'Physico-chemical quality parameters and overall quality index of apple during storage', Journal of Food Science and Technology, Vol. 49, No. 5, pp.594-600.

Jie, D., Xie, L., Rao, X. et al. (2014) 'Using visible and near infrared diffuse transmittance technique to predict soluble solids content of watermelon in an on-line detection system', Postharvest Biology and Technology, Vol. 90, pp.1-6, Elsevier B.V.

Koc, A.B. (2007) 'Determination of watermelon volume using ellipsoid approximation and image processing', Postharvest Biology and Technology, Vol. 45, No. 3, pp.366-371.

Kyriacou, M.C. and Soteriou, G. (2015) 'Quality and postharvest performance of watermelon fruit in response to grafting on interspecific cucurbit rootstocks', Journal of Food Quality, Vol. 38, No. 1, pp.21-29.

Liu, W., Zhao, S., Cheng, Z. et al. (2010) 'Lycopene and citrulline contents in watermelon (Citrullus Lanatus) fruit with different ploidy and changes during fruit development', Acta Horticulturae, Vol. 871, No. 1, pp.543-550.

Mao, J., Yu, Y., Rao, X. et al. (2016) 'Firmness prediction and modeling by optimizing acoustic device for watermelons', Journal of Food Engineering, Vol. 168, pp.1-6, Elsevier Ltd.

Mohd Ali, M., Hashim, N., Bejo, SK. et al. (2017) 'Quality evaluation of watermelon using laser-induced backscattering imaging during storage', Postharvest Biology and Technology, Vol. 123, pp.51-59, Elsevier B.V.

Perkins-Veazie, P. and Collins, J.K. (2004) 'Flesh quality and lycopene stability of fresh-cut watermelon', Postharvest Biology and Technology, Vol. 31, No. 2, pp.159-166.

Perkins-Veazie, P., Beaulieu, J.C. and Siddiq, M. (2012) 'Watermelon, cantaloupe and honeydew', in Tropical and Subtropical Fruits, pp.549-568, Wiley-Blackwell, Oxford, UK.

Perkins-Veazie, P., Collins, J.K., Davis, A.R. et al. (2006) 'Carotenoid content of 50 watermelon cultivars', Journal of Agricultural and Food Chemistry, Vol. 54, No. 7, pp.2593-2597.

Quek, S.Y., Chok, N.K. and Swedlund, P. (2007) 'The physicochemical properties of spray-dried watermelon powders', Chemical Engineering and Processing: Process Intensification, Vol. 46, No. 5, pp.386-392.

Rushing, J.W., Keinath, A.P. and Cook, W.P. (1999) 'Postharvest development and transmission of watermelon fruit blotch', HortTechnology, Vol. 9, No. 2, pp.217-219.

Shamsudin, R., Daud, W.R.W., Takriff, M.S. et al. (2007) 'Physicochemical properties of the Josapine variety of pineapple fruit', International Journal of Food Engineering, Vol. 3, No. 5, pp.1-12.

Showalter, R.K. (1960) 'Watermelon color as affected by maturity and storage', Proc. Fla. State Hort. Sci., Vol. 73, pp.289-293.

Tirkey, B., Pal, U.S., Bal, L.M. et al. (2014) 'Evaluation of physico-chemical changes of fresh-cut unripe papaya during storage', Food Packaging and Shelf Life, Vol. 1, No. 2, pp.190-197, Elsevier Ltd.

Tlili, I., Hdider, C., Lenucci, M.S. et al. (2011) 'Bioactive compounds and antioxidant activities during fruit ripening of watermelon cultivars', Journal of Food Composition and Analysis, Vol. 24, No. 7, pp.923-928, Elsevier Inc. 
Wani, A.A., Singh, P., Gul, K. et al. (2014) 'Sweet cherry (Prunus avium): critical factors affecting the composition and shelf life', Food Packaging and Shelf Life, Vol. 1, No. 1, pp.86-99, Elsevier Ltd.

Wechter, W.P., Levi, A., Harris, K.R. et al. (2008) 'Gene expression in developing watermelon fruit', BMC Genomics, Vol. 9, No. 275, pp.275-287.

Yau, E.W., Rosnah, S., Noraziah, M. et al. (2010) 'Physico-chemical compositions of the red seedless watermelons (Citrullus Lanatus)', International Food Research Journal, Vol. 17, No. 2, pp.327-334. 